\title{
UMA INTRODUÇAO AO ENSINO DE FILOSOFIA A PARTIR DA LITERATURA: A FILOSOFIA DE JEAN-PAUL SARTRE COMO PONTO BASE
}

\author{
Rivelino dos Santos Matos
}

RESUMO: Este artigo tem por objetivo apresentar a construção de um Plano de Aprendizagem em que pese o ensino de Filosofia no Ensino Médio a partir da literatura, tendo como ponto base a filosofia de Jean-Paul Sartre como forma introdutória de aproximação do aluno ao universo filosófico. Para isso, abordou-se a literatura enquanto fresta para adentrar à Filosofia, ressaltando as semelhanças temáticas e questionamentos universais comum ao campo da filosofia. O artigo ressalta ainda, o caráter flexível e atrativo da literatura, a importância da didática do olhar e o uso das TIC com meio de tornar as aulas mais dinâmicas e convidativas.

PALAVRAS-CHAVE: Ensino; Filosofia; Literatura; Didática; TICS.

ABSTRACT: This article aims to address the construction of a Learning Plan in spite of the teaching of philosophy in high school from the literature, with the base point of the philosophy of Jean-Paul Sartre as an introductory way 
to approach the student to the philosophical universe. For this, we will approach the literature as crack to enter the Philosophy, highlighting the thematic similarities and common universal questions to the field of philosophy. The article points out also attractive flexible character of literature, the importance of teaching the look and the use of TIC with means of making the classes more dynamic and inviting.

KEYWORDS: Education; Philosophy; Literature; Didactics; ICT. 


\section{INTRODUÇÃO}

$\mathrm{O}$ rigor argumentativo da Filosofia sempre pareceu ser, ao professor de Filosofia do Ensino Médio, uma das principais dificuldades para o ensino da disciplina, o que faz com que, muitas vezes, a aula de Filosofia torne-se enfadonha e desmotivante para o os alunos, bem como para o professor que vê na resistência às reflexões e questionamentos de temas filosóficos uma problemática para a sua práxis educativa. Nesse sentido, o presente trabalho tem como problema a seguinte questão: como apresentar um plano de aprendizagem que aproxime o estudante do Ensino Médio do conhecimento filosófico? Para isso têm-se como objetivo geral reconhecer na literatura um meio para tornar aulas de Filosofia mais atrativas e menos cansativas; e como objetivos específicos, incorporar as TIC aos planos de aulas, reconhecer a filosofia sartreana como um ponto base entre as duas disciplinas, e evidenciar a literatura enquanto ferramenta para o ensino de Filosofia, aproximando o aluno do Ensino Médio ao universo filosófico a partir da literatura.

É válido supor que no mundo contemporâneo a Filosofia não goza da afeição de boa parte do alunado do ensino médio e ensiná-la tem se configurado um grande desafio a muitos educadores. Cabe ao professor de filosofia buscar alternativas para eliminar tais empecilhos e fazer do ensino de filosofia uma atividade mais prazerosa e convidativa, mais relacionada ao mundo e às vivências dos alunos. Ensinar Filosofia como se fazia há décadas atrás possivelmente não seja mais tão eficiente, pois somos homens do nosso tempo, e precisamos vê-la e debatê-la em sala de aula com novos 
moldes e diferentes didáticas. Nesse sentido entendemos que, com a construção de um Plano de Aprendizagem, o docente de Filosofia poderá relacionar seus conhecimentos filosóficos ao conhecimento da sua sala de aula e com uma perspectiva didática criar ações pedagógicas que rompam velhos paradigmas e aproxime o estudante da Filosofia, sob um olhar mais reflexivo.

Dentro desse pensar a respeito do ensinar Filosofia no Ensino Médio, entende-se a interdisciplinaridade, sobretudo a utilização da literatura enquanto ferramenta para o ensino de Filosofia, como uma possível solução inicial que permite não apenas romper com o rigor argumentativo da Filosofia, mas também flexibilizar e dar maior mobilidade aos temas filosóficos, aproximando-os mais dos alunos e permitindolhes uma relação mais prazerosa com a Filosofia. Assim, conclui-se que a construção de um Plano de Aprendizagem contribuirá efetivamente para o alcance dos objetivos propostos. Dessa maneira, será recorrente nos Planos de Aulas a incorporação das TIC objetivando a elaboração de uma didática mais motivadora, no que tange vivermos em tempos altamente tecnológicos nos quais nossos alunos estão inseridos e atuam como agentes transformadores.

A metodologia abordada neste trabalho foi baseada em pesquisas bibliográficas acerca da relação ensinoaprendizagem do componente de Filosofia para o ensino médio. Baseou-se também nas partilhas de conhecimentos que ocorreram nos fóruns dos componentes ministrados no Curso de Especialização no Ensino de Filosofia Para o Ensino Médio promovido pela UAB/UFBA e na experiência da docência em Filosofia. 
A metodologia pode ser compreendida como sendo a forma de organizar ou ordenar etapas de ação e pesquisa a serem seguidas a fim de atingir determinado objetivo. Em uma ação investigativa, o pesquisador deve elaborar um método de pesquisa e segui-lo para o seu sucesso acadêmico, pois é o caminho ou via para realização de seu trabalho. Mais ainda, a metodologia deve constituir-se ferramenta contínua do professor de Filosofia, seja na construção de um plano de aprendizagem e/ou mesmo na elaboração de suas aulas.

Sendo assim, o presente trabalho primará por um método que possibilite veicular conteúdo, aprendizagem e posicionamento critico no que tange o ensino de Filosofia através da filosofia Sartreana, objetivando a construção de uma ação reflexiva acerca de conceitos filosóficos tendo como "facilitador" a flexibilidade e maleabilidade literária sem, contudo, banalizar a Filosofia. Esse cuidado nos é sugerido no PCNEM (1999): "esse zelo metodológico se justifica na medida em que nem se pode ter a veleidade de pretender formar filósofos profissionais e nem se deve banalizar o conhecimento filosófico".

Faz-se necessária uma metodologia ampla, profunda e pautada em pesquisas bibliográficas que favoreça o enlace entre elementos literários e filosóficos, sem que o aluno confunda e/ou trate como iguais ambas as disciplinas. É importante que o discente perceba suas distinções e contribuições para a compreensão tanto de uma como de outra. No entanto, suas opiniões precisam estar fundamentadas e distanciadas de um censo comum, ao que os gregos chamavam de doxa.

Desse modo, a metodologia que será empregada terá como referência a obra filosófica de Jean-Paul Sartre como 
fonte fundamental e "norteadora" dos conteúdos, discussões, pequenos seminários e avaliações escritas que objetivarão a reflexão a partir das experiências de mundo (existenciais) do aluno para a construção de um pensamento filosófico critico e mais rígido. E mais ainda, que permita ao aluno examinar o problema que a todo o momento se apresenta ao ente (aluno) nas relações com as coisas do mundo, consigo mesmo e com o outro.

Por isso, é importante não esquecermos, ao elaborarmos uma metodologia, o conhecimento de mundo do aluno, sua capacidade investigativa. Segundo Porto (2006, "s/p"), "não basta informar o aluno, apresentar-lhe um conhecimento acabado, porque ele só compreenderá aquilo que ele próprio elaborar, ou seja, aquilo que for resultado de suas investigações intelectuais".

Também serão realizados, para a elaboração do Plano de Aprendizagem, fichamentos dos referenciais e leituras complementares: Ética e literatura em Sartre (2004), A náusea (2006), O muro (2005), A idade da razão (1996), com A morte na alma (1983) O existencialismo é um humanismo (2012) e pesquisas na internet.

\section{FUNDAMENTAÇÃO TEORICA}

O presente trabalho cujo tema que serve como ponto base é o ensino de filosofia a partir da literatura consiste na elaboração de um plano de aprendizagem a ser aplicado no $1^{\circ}$ ano do ensino fundamental. Para isso, será aplicada uma didática fundamentada na dialética, que paute-se no 
construir/reconstruir e que estabeleça um vínculo entre ensino e aprendizagem embasada na teoria educativa de Paulo Freire, fomentado em uma práxis que não se vê pronta e acabada, mas em constante desenvolvimento.

No processo educacional é necessário e impreterível que se reconheça no aluno um fator essencial para toda e qualquer construção de conhecimento. Nesse sentido, é preciso dirimir a idéia arcaica do aluno como receptáculo de conteúdos e inseri-lo em um ambiente educacional em que ele seja construto e construtor de conhecimento. Partindo desse pressuposto reconhecemos na didática um papel fundamental na construção do processo de ensinoaprendizagem.

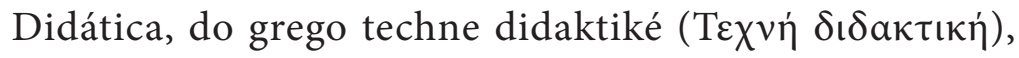
é uma expressão que se pode traduzir por arte ou técnica de ensinar, ou seja, ocupa-se das estratégias de ensino e das metodologias que devem ser elaboradas conforme os elementos e características do ambiente educacional em que o professores e alunos estão inseridos.

Teoria e pratica nem sempre andam juntas, por isso é importante que a didática abarque conteúdos como: espaço escolar, alunos, recursos, comunidade, cultura etc., pois possibilitarão a elaboração de estratégias de ensino que realmente possam ser aplicadas. Assim, considerando a demanda e, mais ainda, a rápida evolução digital/tecnológica que envolve e desenvolve-se na sociedade contemporânea, faz-se essencial que o professor busque praticas que criem mecanismos de construção do conhecimento que abranjam a utilização das TIC. 
Estamos cercados por tecnologias e fazemos uso delas diariamente. Por esse motivo e porque elas forjam subjetividades que ainda não foram percebíveis pela escola, incorporá-las, enquanto recurso didático, para a construção do ensino-aprendizagem constitui uma necessidade da escola às circunstâncias sociais de hoje. Por outro lado, segundo Tânia Maria Esperon Porto (2006, p. 45) as contribuições das TIC como: rapidez, recepção individualizada, interatividade e participação, hipertextualidade, realidade virtual e digitalização/ideologia são potenciais educativos.

Ensinar requer técnica, requer que nos eduquemos ao mesmo tempo em que educamos, que nos transformemos ao mesmo tempo em que transformamos, que nos movimentemos quando causamos movimento, requer sobretudo que desenvolvamos a didática do olhar (ensinar a olhar) para a construção de um efetivo ensino de Filosofia em salas de $1^{\circ}$ ano em que a relação ensino-aprendizagem seja dinâmica e profícua e, mais ainda, que seja uma aula "massa", como se diz na gíria corrente.

Sempre que lemos e/ou escrevemos sobre educação somos conduzidos a pensá-la como transformação, como instrumento transformador do aluno, do aprendiz, do 'ente' que se educa. Mas numa didática do olhar é preferível pensála como movimento, pois toda transformação, a toda pratica pedagógica, toda técnica, toda mudança começa por um movimento.

Para Candau (1984), a didática tem por objetivo o como fazer a prática pedagógica, mas este só tem sentido quando articulado ao que fazer e ao por que fazer. Dessa maneira, estando discutidas as propostas, traçamos possivelmente 
uma discussão acerca da didática. Isto pressupõe movimento constante. Devemos ser homens do nosso tempo, diria JeanPaul Sartre. Já Freire diria que a leitura do mundo precede a leitura da palavra.

O nosso mundo e o nosso tempo é cada vez mais tecnológico, e o uso de novas tecnologias na educação já não suscita dúvidas ou polemicas, mas reflexões pontuais acerca de como nós, professores, nos apropriaremos das TIC. O que fazer e por que fazer uso delas enquanto recurso didático para o ensino de Filosofia?

Talvez o primeiro passo seja começarmos a desenvolver a didática do olhar para que junto com nossos alunos enxerguemos as TIC. Não apenas como diversão, como peças úteis a um determinado fim, mas também como instrumentos de aprendizado, como ferramenta de construção de conhecimento. O segundo passo é ver que falarmos em didática do olhar não é algo desconexo, pois se prestarmos atenção veremos o quão apelativo são as TIC ao olhar. Celulares, tabletes, computadores, vídeos, jogos, apps e etc., nos aprisionam o olhar, ou seja, as inovações tecnológicas apelam a este sentido.

Olhar é conhecer, aprender, é fazer novas descobertas. É o que fazem nossos alunos diante das TIC, e se o professor ainda resiste a essas inovações é porque não entende, porque ainda não aprendeu a ver. Estamos diante de uma geração que aprende inglês diante de imagens de televisão e de jogos de computadores, por menus de celulares, que prefere a tela de um celular a uma folha de papel.

A didática do olhar é, inicialmente, um movimento. E compreendê-la será de grande valia para o ensino de Filosofia 
em que se proponha o uso das tecnologias da informação. A didática é uma tarefa a ser elaborada pelo professor tendo em consideração muitos aspectos, é um papel fundamental para que se estabeleça e se construa a relação ensino-aprendizagem em aulas de Filosofia. No entanto, é sempre um registro, um plano escrito, elaborado, esquemático, e compete ao professor concretizá-lo da melhor forma possível.

Sob tal perspectiva é válido pensar uma didática que tenha como foco uma introdução ao ensino de Filosofia a partir da literatura: a filosofia de Jean-Paul Sartre como ponto base, por se entender como uma ponte que contempla esse olhar investigativo e critico-reflexivo, por se tratar de uma literatura que questiona por um ser existencial, por um mundo e "ser-no-mundo" em que se percebe uma ação, ou melhor, uma filosofia da ação.

O Homem é tão-somente, não apenas como ele se concebe, mas também como ele se quer; como ele se concebe após a existência, como ele se quer após esse impulso para a existência. O homem nada mais é do que aquilo ele faz de si mesmo. (SARTRE, 2012, p. 10)

Isso requer liberdade, e, porque não dizer, uma educação libertadora que possibilite aos alunos conceberem-se livres e construtores de seus próprios conhecimentos e, portanto, responsáveis por essa construção? Segundo Paulo Freire (1998), ou melhor, numa didática freiriana, há uma "exigência" de que na elaboração pedagógica se conceba a educação enquanto pratica libertadora: 
Educação que desvestida da roupagem alienada e alienante, seja uma força de mudança e de libertação. A opção, por isso, teria de ser também, "educação" para a "domesticação", para a alienação, e uma educação para a liberdade. "Educação" para o homem-objeto ou educação para o homem-sujeito. (FREIRE, 1998, p.45).

Para Gerd Bornheim (1986);

O tema da liberdade é ponto central do pensamento e como que resume toda a sua doutrina. Sua tese é insólita: a liberdade é absoluta ou não existe. Sartre recusa todo determinismo e mesmo qualquer forma de condicionamento desenvolvimento. (BORNHEIM, 1986, p.199).

Tanto Sartre quanto Freire têm em seus pensamentos um ponto fulcral em comum: a liberdade como fundamento da subjetividade. Independente de quaisquer forças coercitivas, de quaisquer condições situacionais, é sempre o sujeito responsável por si, por sua própria construção. A teoria educativa de Paulo Freire é norteada por conceitos como liberdade, autonomia, emancipação. Princípios interligados ou como sinônimos para a construção contínua de uma prática educacional libertadora. Outro ponto semelhante entre ambos os estudiosos diz respeito à concepção acerca do homem. Em Sartre temos o ser-aí, lançado ao mundo, não projetado e por fazer-se:

[...] o homem existe primeiro, se encontra, surge no mundo, e se define em seguida. Se o homem, na 
UMA INTRODUÇÃO AO ENSINO DE FILOSOFIA A PARTIR DA...

concepção do existencialismo, não é definível, é porque ele não é, inicialmente, nada. Ele apenas será alguma coisa posteriormente, e será aquilo que ele se tornar. Assim, não há uma natureza humana, pois não há um Deus para concebê-la. O homem é, não apenas como é concebido, mas como ele se quer, e como se concebe a partir da existência, como se quer a partir de elã de existir, o homem nada é alem do que ele se faz. (SARTRE, 2012, p. 19).

Frente a esse conceito de homem em si, Sartre caracteriza a liberdade de escolha, e a posteriori de autonomia. Faz-se importante teoria educacional que valoriza e, sobretudo, conceba o ato educativo como algo libertador e subjetivo. Embora Freire, ao contrario de Sartre, fale de uma "natureza humana", ele a concebe como inacabada, e o homem como um devir. Que busca sempre, e ao mesmo tempo é inacabado:

É uma natureza em processo de estar sendo com algumas conotações fundamentais sem as quais não teria sido possível reconhecer a própria presença humana no mundo como algo original e singular. Quer dizer, mais do que um ser no mundo, o ser humano se tornou uma Presença no mundo, com o mundo e com os outros. Presença que, reconhecendo a outra presença como um "não-eu" se reconhece como si própria. Presença que se pensa a si mesma, que se sabe presença. (FREIRE, 1998, p. 9)

O que se pretende ao traçar essa relação de pensamento entre Paulo Freire e Sartre é evidenciar que ambos comungam ideias acerca da liberdade e da subjetividade 
como necessárias a toda e qualquer transformação e, portanto, fundamentar a escolha da teoria educativa de Freire no que tange a elaboração de um trabalho que pretende introduzir o ensino de Filosofia no $1^{\circ}$ ano do ensino médio tendo como ponto base a filosofia sartreana.

Para isso serão consultadas obras de Paulo Freire para fins didáticos e pedagógicos: Pedagogia da Autonomia (1998), Educação como prática da liberdade (1979), Educação e Mudança (1983) e Pedagogia do Oprimido (1978). Embora Freire se constitua o teórico basilar no que tange a didática deste Plano de Aprendizagem, outros teóricos também contribuirão para algumas pontuações, entre eles: Rodrigo (2009), Rezende (2005), Campaner (2012), Romão (2002), Nunes (2003), Libâneo e outros que eventualmente venham a contribuir para um modelo didático em sala de aula. Quanto às obras de Sartre, serão utilizadas as que mais marcaram sua filosofia, a saber: $A$ náusea (2006), O muro (2005) A idade da razão (1996) e A morte na alma (1983). E ainda, Silva (2004), Rohden e Pires (2009).

Outro ponto que levou a escolha de Paulo Freire a fundamentar esse trabalho foi sua visão frente as TIC.

Não tenho dúvida nenhuma do enorme potencial de estímulos e desafios à curiosidade que a tecnologia põe a serviço das crianças e dos adolescentes das classes sociais chamadas favorecidas. Não foi por outra razão que, enquanto, secretario de educação da cidade de São Paulo, fiz chegar à rede das escolas municipais o computador. Ninguém melhor do que 
meus netos para me falar de sua curiosidade instigada pelos computadores com os quais convivem. (FREIRE, 1978, p. 34)

Freire já antevia a importância dessas tecnologias na construção do conhecimento, hoje provavelmente daria grandes contribuições nesse sentido. O tecnológico é algo concreto e cotidianamente recorrente em nossos dias, está presente em tudo o que fazemos. Portanto, a unidade escolar não pode abster-se desse conhecimento, tampouco contentarse na mera utilização dos recursos dessa tecnologia, mas apropriar-se dessa linguagem, desse conhecimento para desenvolver um planejamento pedagógico que abarque e contemple as nuances da realidade dos alunos. Olhar o mundo sob a concepção dos jovens.

Toda leitura e, por conseguinte, toda interpretação de mundo precede a leitura da palavra. Crê-se que com a Filosofia aconteça o mesmo e, assim, pode-se passar da leitura do mundo para a "leitura" da Filosofia. O ensino de Filosofia a partir do cotidiano, do mundo do aluno. Mundo este conectado e recorrente de novas tecnologias. Para Freire (1983), "a leitura do mundo precede sempre a leitura da palavra e a leitura desta implica a continuidade da leitura daquele".

[...] trazem consigo de compreensão de mundo, nas mais variadas dimensões de sua prática na prática social de que fazem parte. Sua fala, sua forma de contar, de calcular, seus saberes em torno do chamado outro mundo, sua religiosidade, seus saberes em torno da saúde, do corpo, da sexualidade, da vida, da morte, da força dos santos, dos conjuros. (FREIRE, 1998, p. 85-86) 
Em suma, o presente Plano de Aprendizagem objetiva proporcionar um ensino de Filosofia no ensino médio mediado pela filosofia de Sartre numa perspectiva educacional de Paulo Freire, em que se considere a literatura como auxiliadora, como instrumento facilitador para o ensino de Filosofia, enquanto instigadora e, porque não dizer, enquanto um "convite" literário ao mundo da Filosofia.

\section{APLICAÇÃO EM SALA}

O Plano de Aprendizagem aqui exposto se propõe especificamente aproximar o aluno do Ensino Médio do universo filosófico. Para tal propósito serão elaborados dez planos de aulas para a componente de Filosofia, com carga horária de quatro aulas de 50 minutos cada uma e tendo por temas: Ética, Filosofia Política, Ontologia, Filosofia da Linguagem, Teoria do conhecimento, Filosofia da Ciência, Estética, Filosofia da Arte e Modernidade e Liberdade. Este último contará com a realização de uma pesquisa objetivando a aprendizagem investigativa, cujo tema será apresentado pelo professor, bem como os critérios metodológicos atentando para instrumentos que caracterizam uma pesquisa.

Todos os Planos acima citados terão por finalidade: o ensino do conteúdo de Filosofia, o uso da literatura como ferramenta metodológica e a filosofia de Sartre como ponto base, como mediação entre a literatura e a Filosofia, para que se possa estabelecer a indispensável aproximação do aluno 
com a Filosofia. Assim, todos os Planos contarão com uma leitura literária/filosófica de Sartre. Ora estabelecendo uma relação temática entre literatura e Filosofia, ora partindo da literatura para a Filosofia essa intersecção partirá, sempre que possível, do contexto literário sartreano (narrativas e personagens) como forma de "um pensar, de um analisar e questionar a própria realidade do aluno.

Essa mediação far-se-á também através de exposições em sala de aula (seminários, debates, textos) de temas filosóficos presentes nos romances de Sartre. Os conflitos das personagens, as dúvidas e sensações que experimentam servirão como mote dialógico para que o aluno reflita sobre as questões existenciais que permeiam o homem e ao mesmo tempo o colocam como responsável pelo que faz com elas e/ ou pelo que faz de si mesmo. E se a experiência é estímulo ao pensamento, então uma forma de estimular o pensamento dos alunos acerca de questões filosófica é partir de experiências relatadas na literatura, como os fatos corriqueiros, presentes nos romances de Sartre, e que muitas vezes também são comuns no dia-a-dia dos alunos, como por exemplo: andar na praia, atirar uma pedra no mar ou observar a raiz de um castanheiro (acontecimentos presentes em A Náusea) que em Sartre nos permitem uma investigação existencial semelhante à vivida por seus personagens. Desse modo, a leitura (romance), ou "o relato" como diria Matthew Lipman, instigará o pensamento e fará com que os alunos adentrem aos conceitos filosóficos, sem que essa reflexão cause um distanciamento do pensamento radical tão característico da filosofia. 
Outra forma como se tecerá essa mediação é através de vídeos e textos na internet que exponham os conceitos filosóficos sartreanos para em seguida buscá-los nas obras romanescas do filósofo (textos de Sartre previamente selecionados), convidando assim o aluno a não só refletir as questões filosóficas como também lhe permitir perceber tais questões "diluídas" de maneira menos rígida através da literatura para assim melhor compreender os conceitos do filósofo (já nos moldes radical/rígido do pensamento filosófico). Dessa maneira, acredita-se ser possível a intersecção entre a filosofia e a literatura sartreana de modo a atender os objetivos propostos.

Também presente e não menos indispensável na elaboração dos planos será a realização de atividades que necessitem ou nas quais se possa utilizar as TIC como ferramentas de pesquisa e acessos a conteúdos temáticos (busca no Google, Wikipédia, criar grupos no facebook e WhatsApp, leitura e downloads de obras filosóficas e romances de Sartre etc.) por meio de tablets e celulares não apenas como fonte de pesquisa, mas também por seu caráter lúdico e prazeroso, pois considerando os tempos de globalização e de sociedade altamente informatizada em que vivemos é producente que façamos uso das tecnologias que cotidianamente nos cercam.

Embora não seja objetivo desse trabalho, sua efetiva realização coaduna a reflexão de algumas características de nosso tempo, a saber: as TIC no cotidiano e o acesso do conhecimento na sociedade de informação, acarretando quiçá uma intervenção pedagógica (tendo em vista a resistência de muitas escolas no uso dessas tecnologias) que privilegie o uso as Tecnologias de Informação e Comunicação. 
Em suma, os Planos de Aula não só aproximarão o aluno do universo filosófico como também permitirão ao professor de filosofia ensiná-la de modo crítico, reflexivo e condizente com a realidade do aluno, dando à Filosofia menos rigor tanto pelo uso das TIC como pelo uso da literatura. $\mathrm{O}$ objetivo dos Planos não se restringe à aproximação da Filosofia por parte do aluno do Ensino Médio, mas, consequentemente, introduzir novas ferramentas que permitam ao sujeito pensar, romper padrões de mundos e ideias com as quais se relacionam e estabelecer novos e elaborados questionamentos, pois filosofar é em certo aspecto um fazer na ausência da realidade enquanto objeto concreto é "bulinar o real para descortinar o sensível", por esta razão a literatura, esse mexer o real, esse imaginar se.., se mostra instrumento facilitador não só para o aprendizado da filosofia, mas para o desvelar do mundo e, por conseguinte, do próprio Ente.

\section{CONSIDERAÇÕES FINAIS}

O ensino de Filosofia no Ensino Médio sempre teve em seu bojo algumas dificuldades fulcrais, a saber: o rigor argumentativo, o vocabulário altamente técnico e o distanciamento do cotidiano do aluno. O que se aduz dessa argumentação é que o ensino de Filosofia no Ensino Médio carece de uma aproximação com a realidade do aluno, com seu cotidiano e "conhecimento de mundo". É um ensino que muitas vezes parece distante das experiências dos alunos. 
Tal "distanciamento" acaba por acarretar a falsa idéia de que a filosofia é algo restrito ao universo acadêmico, sem espaço ou sentido em outros lugares. Isso contribui para uma resistência às aulas de filosofia, tornando-as enfadonhas, desmotivantes para o aluno e também para o professor.

Desse modo, o intento do presente trabalho foi pender para questões que possibilitassem a construção de um plano de aprendizagem cujo objetivo seja aproximar o aluno do Ensino Médio ao universo filosófico. Se as Orientações Curriculares Para o Ensino Médio propõem despertar no aluno o interesse pela reflexão filosófica, bem como uma capacidade e habilidade argumentativa, quase sempre apoiados na tradição, no entanto, isso não significa começar, necessariamente, pelos autores clássicos e/ou mesmo pela linguagem própria da filosofia.

Assim, parece mais facilitadora uma metodologia que se utilize da linguagem cotidiana dos alunos, que seja reflexiva da realidade vivida pelos alunos, possibilitando que a filosofia tenha maior significado frente aos educandos. Essa linguagem mais cotidiana, mais informal e representativa da realidade do aluno é comum à literatura. Uma linguagem mediadora, facilitadora para o ensino de filosofia no ensino médio, pois permite ao aluno ir aos poucos universalizando seu olhar, habilitando-os e aproximando-os de outros saberes, de outras formas argumentativas, a exemplo: a Filosofia, menos imagética, mais formal e incisivamente analítica e questionadora.

O uso da literatura no ensino médio enquanto ferramenta para o ensino de Filosofia compõe uma metodologia que parte do olhar apurado e imagético (situações e cenário narrados, 
subjetividade das personagens etc.) da literatura mesmo que informal, ficcional, e não menos real enquanto possibilidades lógicas de manifestar-se na realidade para uma argumentação formal, argumentativa e filosófica.

Se a ficção imita e/ou corresponde ao real e as ideias são oriundas das experiências então se pode afirmar que a literatura é uma representação dessas experiências, suas situações narradas são passiveis de ocorrerem na realidade e, portanto, conduzem ao questionamento, ao dar sentido aos porquês? Esse "pensar literário/subjetivo" pode propiciar e, porque não dizer, facilitar a introdução do ensino de Filosofia no Ensino Médio, constituindo-se em um instrumento privilegiado para se "ensinar" Filosofia. Sartre, ao escrever seus romances, teve a clara intenção de expor seus conceitos filosóficos para conduzir seus leitores às reflexões filosóficas existencialistas. A partir da obra de Sartre, não seria nenhum absurdo pensar a literatura enquanto escolha filosófica, uma ferramenta vantajosa para a comunicação de sua filosofia através de personagens romanescas.

Sendo assim, pensar um plano de aprendizagem para o ensino de Filosofia no $1^{\circ}$ ano do Ensino Médio é não somente relevante como também um meio facilitador para a introdução da Filosofia a alunos do Ensino Médio. Nesse sentido, ensinar Filosofia tendo como ponto base a filosofia de Jean-Paul Sartre configura nesse trabalho essa ferramenta facilitadora, mediadora e preparatória ao ensino de filosofia de modo mais prazeroso, menos resistente e muito mais profícuo. A escolha por Sartre evidencia a aproximação e/ou a possibilidade de aproximação, de dialogo, entre Literatura e Filosofia. Mais ainda, a Literatura como vinculo, como ferramenta de ensinar Filosofia. 
Filosofia e Literatura dialogam entre si, pois abordam temas que são universais e proporcionam a reflexão criticareflexiva. A literatura possui uma leitura imagética da realidade, que conduz a experiências vividas no cotidiano, com as coisas do mundo. Literatura é o tomar conhecimento dos fenômenos possíveis ou não, vividos ou imaginados. Isso permite adentrar ao questionamento, desperta duvidas. A filosofia é o ato constante de questionar, é o educar da razão. Aciona pensamentos, desperta o desejo do conhecimento. Desse modo, compreende-se a literatura como meio importante para a condução do aluno a esse questionar, a esse pôr em movimento o pensar que tanto caracteriza a Filosofia, além de tornar mais prazeroso menos "conceitual" o ensino de Filosofia no Ensino Médio.

Conclui-se que o Plano de Aprendizagem apresentado viabiliza o ensino de filosofia de modo a romper as resistências iniciais da maioria dos alunos à disciplina, bem como favorece um aprendizado mais enriquecedor se considerado a interdisciplinaridade entre formas de saberes distintas e harmônicas. Caráter também fundamental nesse trabalho é o uso das TIC, que por se tratar de algo comum ao uso cotidiano dos alunos, e que permeia os contextos escolares, familiares e sociais acabam por agregar riqueza ao Plano de Aprendizagem apresentado.

A tecnologia tem estado cada vez mais presente na sociedade na medida em que se torna ferramenta para as mais diversas ações: trabalho, comunicação, lazer etc., ou seja, vivemos a era da informação digital e nossos alunos são abarcados, influenciados e naturalmente se apoderam desse conhecimento. Assim, trazer o uso das TIC para a sala de aula 
não apenas enriquece o trabalho do professor como favorece a criação de um ambiente mais "lúdico" e motivador, visto o fascínio que nutrem os jovens por essas tecnologias.

Por isso, crê-se na possibilidade de aplicação desse Plano de Aprendizagem, não esquecendo a difícil tarefa em inserir as novas Tecnologias de Informação e Comunicação (TIC) aos planos de aulas, uma vez que existem “opiniões" muitas vezes desmotivantes de colegas professores com relação ao uso das TIC, que junto a já diagnosticada resistência dos alunos do Ensino Médio à disciplina de Filosofia configuram as principais dificuldades na implementação deste Plano de Aprendizagem.

Por outro lado, seu caráter desafiador, a incorporação das TIC, a abordagem da literatura como ferramenta de introdução ao saber filosófico, a possibilidade do professor de filosofia estruturar melhor suas aulas, e mais ainda, a troca de saberes entre aluno x professor sempre que os conteúdos forem relacionados à realidade dos educandos constituem as principais contribuições do Plano de Aprendizagem.

\section{NOTA}

${ }^{1}$ Especialista em Lingüística e Literatura pela Faculdade Zacarias de Goes (FAZAG) e Especialista em Ensino de Filosofia no Ensino Médio pela Universidade Federal da Bahia (UFBA).E-mail: rivelinomatos@hotmail.com 


\section{REFERÊNCIAS}

BORNHEIM, Gerd. A. Debates de filosofia: Sartre - Metafísica e Existencialismo. São Paulo: Perspectiva, 1986.

CABRAL, J. F. P. A Estética na Filosofia de Platão e Aristóteles. Brasil Escola. Disponível em: <http://www.brasilescola.com/ filosofia/a-estetica-na-filosofia-platao-aristoteles.htm.>. Acesso em: 01 ago. 2015.

CANDAU, V. "A didática e a formação dos educadores" - da exaltação à negação: a busca da relevância. In: CANDAU, V. (org.). A didática em questão. Petrópolis: Vozes, 1984a. p. 12-22.

FREIRE, P. Pedagogia da autonomia: saberes necessários à prática educativa. Rio de Janeiro: Paz e Terra, 1998.

FREIRE, P. Educação como prática da liberdade. Rio de Janeiro: Paz e Terra, 1979.

FREIRE, P. Educação e Mudança. Rio de Janeiro: Paz e Terra, 1983.

FREIRE, P. Pedagogia do Oprimido. Rio de Janeiro: Paz e Terra, 1978.

LIBÂNEO, J. C. Didática. São Paulo: Cortez, 1990.

SARTRE, Jean-Paul. O existencialismo é um humanismo. Petrópolis-RJ: Vozes, 2012. 
UMA INTRODUÇÃO AO ENSINO DE FILOSOFIA A PARTIR DA...

SARTRE, Jean-Paul. A náusea. Rio de Janeiro: Nova Fronteira, 2006.

SARTRE, Jean-Paul. A idade da Razão. Tradução Sergio Milliet. Rio de Janeiro: Saraiva de Bolso, 2012.

SARTRE, Jean-Paul. Com a Morte na Alma. Tradução Sergio Milliet. Rio de Janeiro: Saraiva de Bolso, 2012.

SILVA, F. L. E. Ética e Literatura em Sartre. São Paulo: UNESP, 2004. 